\title{
What, exactly, is carpal tunnel syndrome?
}

\author{
By Thomas W. Ricks \\ Science Reference Librarian \\ University of Colorado at Colorado Springs
}

\section{A look at an increasingly common work-related disorder.}

arpal tunnel syndrome is a debilitating disorder that is threatening the health and well-being of too many people in this country. Approximately 19 million Americans are disabled each yearfrom cumulative trauma disorders (CTDs), such as carpal tunnel syndrome. CTDs are characterized by repetitive motions for prolonged periods of time that result in injury. Such injuries include

\section{In 1981 CTDs accounted for $18 \%$ of the 126,000 occupational ill- nesses. By 1989 this number had risen to $52 \%$ of the 283,700 cases.}

not only carpal tunnel syndrome, but tendonitis, tenosynovitis, and other inflammatory ailments of the upper arms, shoulders, and back. The associated cost (direct and indirect) is estimated at $\$ 100$ billion annually.

In 1981 CTDs accounted for 18 percent of the 126,000 occupational illnesses. By 1989 this number had risen to 52 percent of the 283,700 cases. $^{2}$ Gerald Scannell, head of the Occupational Safety and Health Administration (OSHA), has labelled CTD as the "occupational disease of the 1990s."

\section{Causes and treatment}

The carpal tunnel is the passageway for the nerves and tendons passing through the wrist and extending into the hand and fingers. The actual "tunnel" is composed of bones and ligament. Since the tunnel is narrow, inflammation and swelling resulting from overuse and continuous flexing causes pressure and compression on the median nerve. The median nerve provides sensation to the hand and fingers. The results are the classic signs and symptoms of carpal tunnel syndrome:

- numbness or tingling sensation in the hands and fingers;

- pain in the wrist, which may radiate up into the forearm or down into the hand or fingers;

- numbness or pain may be intensified at night.

If the condition is identified early, conservative therapy can be initiated and hopefully surgery can be avoided. Conservative therapy consists of splinting the hand and forearm, taking anti-inflammatory agents such as aspirin or ibuprofen, and starting an exercise program designed to strengthen the affected area.

Without alterations in the work environment, however, therapy of any kind is of little use. The circumstances associated with the onset of the disease must be resolved or the injury cycle will likely continue.

The cost of surgery is very expensive compared to conservative therapy; over $\$ 20,000$ for the surgery, lost work time, disability payments, and rehabilitation. Furthermore, surgery is not always effective and even if it is, the likelihood of reoccurrence is high. ${ }^{4}$ Therefore, the emphasis must be on prevention not treatment. 
The increase in the incidence of carpal tunnel syndrome is directly related to automation in the workplace and the ethic of "increase productivity." Jobs are being simplified into smaller more repetitive tasks so that people can work faster and longer while producing more. Computers allow people to type much faster than was ever possible on typewriters; ther's no changing paper, using white-out, or pausing after the end of each line, there's only rapid continual motion.

\section{Prevention}

Clearly, prevention is the answer to solving the carpal tunnel syndrome question. By initiating some basic changes in the workplace much can be done to reverse the high incidence of carpal tunnel syndrome and associated suffering. These changes include:

- provide properly designed work stations and keyboards, includinghigh-quality ergonomic chairs that adjust to the user;

- encourage adequate rest periods to stretch and relax hands;

- include job rotation where possible;

- implement a long-term educational program for all employees, including supervisors, as to the causes and methods for prevertion.

\section{Conclusions}

As libraries continue to implement new technologies and attempt to do more with fewer resources, the risk of developing carpal tunnel syndrome among library employees will increase even more.

It is imperative that libraries with unsafe working conditions initiate preventative measures now before the problem grows worse. Librarians have the responsibility to ensure that the library is a safe place to work for all.

\section{NOTES}

${ }^{1}$ Greg LaBar, "Bent out of shape," Occupational Hazards (June 1991): 37-39.

${ }^{2}$ U. S. Department of Labor, Bureau of Labor Statistics, Bulletin 2379 (Washington, D.C.: Government Printing Office, 1989), pp. 5, 46.

${ }^{3}$ Barbara Goldoftas, "Hands that hurt: Repetitive motion injuries on the job," Technology Review 91 (January 1991): 42-50.

${ }^{4}$ Michael Schachner, "Treat symptoms before it worsens: Experts," Business Insurance 24 (September 1990): 30-31.

\section{ChernoLit $^{\mathrm{TM}}$}

\section{[ЧерноЛит]}
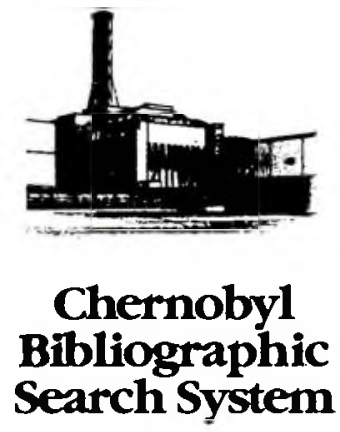

Battelle Software Products is proud to announce ChemoLit, an extensive bibliographic search system about the Chernobyl nuclear accident. ChernoLit contains 4,500 references and abstracts in an easy-to-use format and allows users to interactively search the bibliographic data through menu-driven software. With yearly updates you can be assured it is one of the most complete bibliographic sources for Chernobyl research.

The releases from Chernobyl and subsequent data collection present a resource for evaluating historical risk, transport and deposition models using extensive real-world data. Previously, these models were based on laboratory experiments, theoretical calculations, simulated accidents and limited real data.

ChernoLit is provided on high density floppy disks and is easily installed on an IBM PS/2, AT or fully IBM-compatible PCs.

The cost is $\$ 395.00$ each (U.S./Canada) and $\$ 500.00$ each (international). All titles and abstracts are written in English. To place an order please call 1 800-451-3543 or (614) 424-6393. For more information call (509) 375-6787.

All prices U.S. dollars only. Applicable sales tax for the following states: CA, CT, KS, MA, MD, MS, NY, OH, PA, SC, TN, TX, UT, VA, WA.

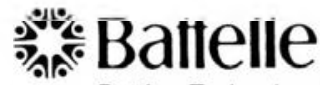

Putting Technology To Work 